\title{
Meanings, beliefs and attitudes of the neonatal unit staff in México about the parents' participation in a neonatal unit: A qualitative approach
}

\author{
Josefina Gallegos Martínez, Jaime Reyes Hernández \\ Universidad Autónoma de San Luis Potosí, San Luis Potosí, México. \\ Correspondence: Josefina Gallegos Martínez. Address: Universidad Autónoma de San Luis Potosí, San Luis Potosí, \\ México. Email: joga2002@hotmail.com \\ Received: December 17, 2013 Accepted: February 2, $2014 \quad$ Online Published: March 26, 2014 \\ DOI : $10.5430 /$ jnep.v4n5p159 \\ URL: http://dx.doi.org/10.5430/jnep.v4n5p159
}

\section{Abstract}

Background and context: The two most important factors and determinants of morbidity and mortality of the newborn are prematurity and low birth weight, children are admitted in neonatal unit and require many specialized therapeutic interventions, thus, a medical and technical focus is predominating. The staff of neonatal unit has a challenge in provide support to parents' participation in the care of their child. The study was performed in a public hospital offering second-level care in San Luis Potosí, México.

Purpose: To identify and analyze the meanings, beliefs and attitudes of the neonatal unit staff about the Mexican parents' participation in the care of hospitalized preterm neonates.

Design and Methods: A qualitative research study was conducted at a neonatal unit in México. Data collection consisted of semi-structured and recorded in-person interviews with staff who signed an informed consent. The analysis method used was content analysis in its thematic mode.

Results: The results summarize the most relevant information of the meanings, beliefs and attitudes of the health professionals- benefits, barriers, encouragement-, about the parents' participation in a Mexican neonatal unit. Three themes emerged: The parental participation benefits the hospitalized premature infants; restriction and barriers for parents' participation; encouragement of parents’ participation.

Conclusions: The staff considered parental participation to be important, and they therefore proposed certain changes to promote participation based on a system of teamwork and a transformation of the hospital rules, emphasizing the experiences of parents in the NU and supporting their emotional responses and feelings. The participants thought that they should be teaching about childcare. However, controversy was revealed among the practitioners regarding parental involvement with respect to gender, particularly the idea that the mother should be the main presence whereas the father should be a recipient of information, despite expressing a positive view of the father's inclusion and his right to take care of his child.

Summary: The hospitalization of premature neonates produces separation from their families. Parental visit to NUs in México depends on factors such as human milk production, neonate clinical conditions and medical treatment. It also depends on the meanings, beliefs, attitudes of the health team concerning the parents' participation. This study provides information on parental participation to promote unrestricted access to the neonatal unit. 
Potential implications: The construction of a model of family participation based on a framework of parental participation in the NICU.

\section{Key words}

Neonatal nursing, Premature, Parents, Attitude, Qualitative Analysis

\section{I ntroduction}

Preterm birth is a global perinatal health problem. In 2005, there were 12.9 million preterm births (9.6\% of the total number of births), of which 0.9 million occurred in Latin America and the Caribbean ${ }^{[1]}$. Stephens and Vohr reported that the epidemiological profile of preterm birth has changed regarding the survival rate because even babies with the lowest birth weights survive at higher rates due to technology and available treatments. Rates of neonate survival were 55\% for 501- to 750 -g infants, $88 \%$ for 751 - to 1000 -g infants, $94 \%$ for 1001 - to 1250 -g infants, and $96 \%$ for 1251 - to 1500 -g infants born between 1997 and $2002^{[1,2]}$.

In México, approximately 8 to 10\% of children are born before 37 weeks of gestation. Of every 100 children who die annually before completing one year of life, between 40 and 60 are born before 32 weeks of gestational age and die before the age of 28 days of life. The two most important factors and determinants of morbidity and mortality of the newborn are prematurity and low birth weight ${ }^{[3]}$. Approximately 30 to $60 \%$ of neonatal deaths occur in children who weigh less than 1500 g, and between 60 and $80 \%$ of admissions to neonatal intensive care units (NICUs) are premature. Prematurity coupled with asphyxia, infectious disease, and breathing problems, are the main causes of mortality and admission to neonatal special care units. In 2011 in San Luis Potosí, there were 48,218 births, of which more than 50\% occurred in hospitals, and $13 \%$ of these were preterm or had a low birth weight ${ }^{[3,4]}$.

Derived of this morbidity, preterm neonates admitted to the neonatal unit require many specialized therapeutic interventions of health personnel. Training nurses and physicians provide care to recovery the preterm neonates, therefore, their activities are focused in procedures in this care environment. In NUs still a medical and technical focus is predominating ${ }^{[5,6]}$. In accordance with Wigert the staff of NU have a challenge in provide support to parents' participation in the care of their child ${ }^{[7]}$.

The parents' participation in NUs could mean different things to staff. According with Boukydis, is a challenged for educational necessities of the parents, thus, some UNs provide supporting parents with supervision of nurses and physicians, while, in other NUs the health team feel that they have a lack of preparation and that does not have administrative recognition to support the participation of parents ${ }^{[8]}$.

In accordance with Wigert, et al. ${ }^{[9]}$, there is a need to develop a family-friendly environment that provides optimal conditions for parents to be with their child in a NICU. The parents and babies have the right to stay together during hospitalization, the parents have right to participate in the care of their hospitalized child, and develop their competence in caring for the child at home after discharge ${ }^{[10]}$. In this case, unrestricted parental inclusion in the NU should be implicated, for example, when the mother participates in maternal activities such as feeding and skin-to-skin contact result in an empowered mother and a close relationship within the mother-child dyad. Therefore, the hospitalized children and their parents will benefit from these changes because they may result in biological and psycho-social advantages due to the closeness and bonding between parents and children ${ }^{[5,11]}$.

Researchers discuss about the factors that intervene in the parents' participation in the care of their child in a NUs. In case of the parents, researchers emphasize on the needs of information, to establish interaction with children and take part and the control of the care of their child. The attitudes and activities of healthcare professionals obstacle or provide facilities to parent participation. They emphasize on attitudes of nurses, the difficulties in communication enter parents and staff, the nurses and doctors cannot perceiving that their communication with parents have some problems, and in the integration of 
the mothers' and nurses' tasks or lack on negotiations, the nurses do not want lose the control, which results in difficulties for involving parents in the care of their child ${ }^{[12-14]}$.

Although initiatives have been developed to improve the quality of care, there is still a struggle for closeness between parents and infants during hospitalization.

Although it has been shown that parents have the right to visit and participate in the care of their child hospitalized in the neonatal unit, in the vast majority of the NUs in San Luis Potosí, parents visit is restricted to an average of a couple of hours a day according to the rules of visiting of the hospital. The staff considers that the baby's clinical condition, procedures of diagnosis and treatments and some characteristics of parents are criterion for allow the visit or not, and the guidance that parents receive with respect to child care is not based on a structured program and it is not provided in a systematic way ${ }^{[6,15]}$.

In accordance with the synthesized above, we analyze the meanings, beliefs and attitudes of personnel how factors that facilitate or difficult the parents' participation in a neonatal unit of great importance and tradition for neonatal assistance in San Luis Potosí.

\section{Methods}

\subsection{Design}

We carried out a descriptive and qualitative study. This approach was chosen in the sense that knowing a phenomenon, involves research to describe and interpret from the emic perspective (in this study, the parents in an NU). In this sense, the parents' participation in the neonatal unit from the perspective of health professionals in México, is unknown ${ }^{[16,17]}$.

The knowledge and results from studies concerning the participation of parents in the care of their hospitalized, premature infants was the reference framework. The categories in similar studies allowed focus on questions of the interviews to obtain the traits and relevance of the reality in this study and its significance for the interviewees ${ }^{[18]}$.

The study setting. A NU of a public maternity hospital in the city of San Luis Potosí, México. This regional second-level care hospital tends the rural and urban low-income and middle class populations from San Luis Potosí State and other neighboring states. The mission of this hospital includes caregiving, teaching, and research. In the maternity hospital, there was an average of 270 births each month. In one year, the total hospitalized population in the NU was approximately 608 patients.

Newborns who are hospitalized in the NU are categorized based on the classification outlined by Jurado Garcia ${ }^{\text {[19] }}$. Approximately $60 \%$ of hospitalized preterm infants were low-weight and extremely low-weight. The five leading causes of hospitalization were as follows: Infected Newborn/Sepsis (13.8\%), Respiratory Distress Syndrome (11.5\%), Preterm Newborn (9.5\%), Low APGAR or Neonatal Depression (2.6\%), and Perinatal Asphyxia (2.5\%). Demographic characteristics of the population the hospital cares for include young people with incomplete schooling, rural living, and lower social status ${ }^{[20]}$.

\subsection{Population}

We consider practitioners as humans contextualized in the history and culture of being a provider of neonatal care in the neonatal unit. Therefore, the interviewed participants represent the context of a particular NU, however, with similar health care system to other NUs in San Luis Potosí. The participants in the study included 10 health team professionals who were conveniently recruited to represent four types of disciplines that provide assistance in the NU, to obtain the 
variation in the sample to explore the unique or common manifestations according to our topic of interest, in order to observe the trends ${ }^{[16]}$.

For this study, these professionals were named with the initial capital letter of their profession. The participants included three doctors (Doctor 1; D1...D3); five nurses (Nurse 1; N1...N5), a psychologist (Ps), and a technical-level social worker (SW) (see Table 1). The order of number does not imply the order of interviews but rather the shifts in the NICU. All of these professionals had been working in the hospital and in the NU for more than 10 years.

Table 1. Participants of study

\begin{tabular}{llll}
\hline Interviewees & Sex & Specialty/degree & Shift \\
\hline Nurse Chief & F & Bachelor & Morning \\
Nurse & F & Bachelor & Morning \\
Nurse (2) & F & Bachelor & Evening \\
Nurse & F & Bachelor & Night \\
Doctor Chief & M & Neonatologist & Morning \\
Doctor & M & Pediatrician & Morning \\
Doctor & M & Pediatrician and Master & Night \\
Psychologist & F & Bachelor & Morning \\
Social worker & F & Technical-level & Morning \\
\hline
\end{tabular}

\subsection{Ethics}

The project was approved by the Ethics and Research Committee of the nursing faculty. The participants agreed to participate in the interview and signed the informed consent form.

\subsection{Data collection}

Data were collected from November 2008 to June 2009 through semi-structured interviews. The interviews were conducted to open, expand, and deepen communication ${ }^{[18]}$. Data were collected through semistructured interviews, which contained the interviewee's identification data and were guided by the open main question: "Could you tell me what you think about the participation of the parents of premature children hospitalized in a neonatal unit?", "How do parents participate in care of their premature child at this neonatal unit?, What do you suggest to favor parental participation at the neonatal unit?”. The interviews were conducted in the hospital, in an office to isolate them from environmental distractions. The interviews were conducted face-to-face; each participant had the opportunity to talk freely and to clarify their answers, the participants could illustrate them with examples. The interviews were conducted by the primary investigator of this study and the participants spoke in Spanish for an average of 45 minutes, and each interview was recorded in its entirety and was later transcribed verbatim for analysis.

\subsection{Analysis}

The method used was thematic analysis in its interpretive approach, according with Bardin, is transverse, through a scheme of categories projected on the content to discover similarities, tendencies, and differences. Consisted in three steps.

\subsection{Pre-analysis}

Performed by the primary investigator through of fluctuating reading, discovering the initial clues, and quality rules were applied, exhaustiveness and representativeness, that is, all the elements of communications were analyzed without excluding anything; the communications were concerned and adequate with the same subject and purpose of the study (uniformity and importance). Through of recognized categories in the literature related to the participation of parents in the 
neonatal unit, similar and different trends in the text were searched, from which analysis codes were developed and organized with standardization or equivalence of the trims in communications ${ }^{[21]}$.

\subsection{Exploration of the material}

The material was read and reread to classify and aggregate the data and thus to build theoretical and empirical categories, which were intended to go beyond the obvious meanings to discover the relationships between semantic structures and the meanings of the communication. A total of 20 mutually exclusive sub-themes were obtained.

\subsection{Treatment and interpretation of the obtained information}

All of the researchers discussed and debated each category carefully to validate it through comparison within the reference framework. Thus, three categories emerged grounded in the meanings (relevancies), beliefs concerning participation and attitudes towards participation ${ }^{[21]}$.

\section{Results}

Neonatal assistance in Mexican neonatal units has in common the assistive technology for the biological recovery of prematurity. There are few NUs that consider family inclusion. There is a frame of reference to provide care to these families as it could be 'Family-centered care'. For this reason, the interest of researchers focuses on recovering the actors' perspective about the topic of interest.

The following themes of parents' participation in the NU emerged from the staff's perspective: 1) The parental participation benefits to hospitalized premature infants; 2) Restrictions on and barriers to parents' participation; and 3) Encouraging parents’ participation.

\subsection{The parental participation benefits to hospitalized preterm infants}

It is important to note that participation in premature childcare could have an institutional philosophy framework, which barely exists in most of the hospitals in México. The professionals mentioned ideas of interaction and bonding related with participation. The health professionals believed that parental participation had benefits for interaction within in the mother-child dyad. In the view of the psychologist, participation develops attachment: ...the most important thing is to ensure the formation of the mother-child bond...Ps1. A pediatrician confirmed this idea by stating: ...the bonding is not formed when they are separate ... a child needs it much more when he is (in the NU) stressed and intubated ...D2. A pediatrician and nurse said they gave more importance to the mother's participation based on her reproductive function:...the fathers' participation is very important, but, obviously the mother's one is more relevant, because she was the one who was pregnant ...D2. They gave importance her nutritional function and interactive function with her baby: ...preference to the premature or baby's mother is always given due to breastfeeding, but there is another aspect, it is given to promote maternal attachment ...N1

Participation is very important for the reduction of sequels and the duration of hospitalization; participation also aids in health recovery. This idea was conveyed by a pediatrician: ...it decreases the period of hospitalization, increases his recovery, and reduces the chances of complications and damage in this child ...D1. One nurse believed that the growth and development of children is aided when mothers stimulate their babies: ...coexisting with the baby helps his stimulation, growth, and development ...N4. And a nurse encounter the significance of mothers 'participation through the Mother Kangaroo Care program: ...in several occasions, I gave them to the mother as mama Kangaroo... checking the temperature and the child's neurological status...he needs to be feeling his mother's heart, which is an affective and auditory stimulation ...N3 


\subsection{Restrictions and barriers for parents' participation}

From a medical perspective, the mother must undergo a process of adaptation to the environment of the NU, know the status of the child's health, and know when she can participate, as described by a doctor: ...the mothers have a no active participation, they can enter, watch him, talk to him, but they cannot touch him because that can destabilize him in his critical stage, they can only feed him and visit him... as the baby evolves, she starts having a more active role in tactile stimulation, talking to him, and, obviously, being aware of the monitors is ... the mother must know the situation of her child, get familiar with the devices around, understand that there are moments in which she can actively participate and others in which she cannot ...D3

Participation is also limited by several institutional factors, which include institutional work schedules and routines: ... entrance is limited in the morning, because it is the time for the doctor's visit, taking x-rays, taking laboratory samples, then, the attachment is more favored during the afternoon ...N2. The space in the NU is also a limiting factor for the parents to be included in the care: ...the areas are very reduced, so a nurse and two mothers there can saturate the space ...Ps1. However, in some cases, participation is possible and beneficial despite the small space: ...a baby, who weighed less than a kilogram, was never intubated or in prolonged treatment with parenteral liquids; she never suffered from an infection or something similar. Due to this, I think her participation was highly opportune since this is a very small area and it is more difficult to stay there ...N4. The lack of personnel limits the attention to the parents and their participation: ...(to support parents) there are less nursing staff in the night shift, and the doctor on call is almost for all of the hospital ...N4

Parents' emotions and feelings are influenced by nurses allowing entry to the NU. The providers believe that permission to enter the NICU reduces maternal anxiety, and mothers argue less with nursing staff because they are informed and have contact with their child: ...there are parents who talk to their children, they tell them something and you get (surprised), and so when I see parents who are really interested, I allow them to enter... if we permit mothers to enter to the NU to hold their babies, that helps them to reduce anxiety, because if they are anxious, then they argue with us, however, with the permission and the information about the evolution of their babies, the mothers calm down ...N5

However, the staff considers that the conditions and characteristics of parents, such as low maternal education and poor initiative to participate in care, limit participation: ...with some mothers, I have seen that, because of their level of education, they do not understand the instructions, although we repeat the information ...N5 ...most of the mothers participate because the staff pushes them...the mothers' ideas are passive ...D3

Because of their age, teen mothers do not fully understand how to care for their child. Based on the requirement that someone must take responsibility for what happens to the child, another family member is often involved in the care of the hospitalized baby, even though it is not part of the institutional standard: ...there are many births that are the products of teenagers who have no idea of what we are doing (treatment)...(if) the mother is under-age, in many cases, it is the grandmother who is given the opportunity to participate ...D3

Living in a rural area is a barrier to participation because it favors maternal absence and abandonment, described to the social worker: ...there are families who leave the patient, there are mothers who have their baby, then, they are gone to their farm, to their homes and may not see him for days and leave him here ...SW1. From the nursing perspective, parents from rural areas are not suitably prepared for contact with their child because of their poor hygiene, although they sometimes are given access to a bath: ...there are families who come from the periphery, come from a rural area, then, in fact, for this reason we also restrict access of family members because when they arrive at the hospital, their conditions are not very (hygienic)...(therefore) sometimes, very sporadically, they have been supported with baths and accommodations ...N1 
The staff emphasize that parental involvement is more important than any other factor in the event that the hospitalized child has a poor prognosis: ...parents have the right to see him closely, to touch him, above all when the baby is seriously ill, and when they know that they have a poor prognosis ...N5. The staff has also perceived lack of interest on the parents' side: ...half of that $10 \%$ (of parents who attend the NU) are those who are interested in participating, and others only bring maternal milk to the hospital ...D1. The father has low participation, especially during his working hours: ...the father has little participation, it is difficult in the morning, I think that his work is a (cause), and another one is the fact of being a man, which is something that would have to be modified because they also have the right to participate ...D3

Therefore, the staff believe that it is important that parents take their parental roles seriously, assume responsibility for the child, and be able to participate: ...(to make parents) feel responsible for their son, because he is son of a couple... participation is important ...D2 ... We support and reinforce that the role of a mom can be welcome and well-accepted by them...Ps1

\subsection{Encouraging parents' participation}

To achieve the goal of participation, interdisciplinary and joint work is required: ...real interdisciplinary work, in which we are speaking the same language or all of us are seeking the same goals and working in conjunction and communication very directly, constantly and continuously, that on the one hand, and on the other hand, to have better designed and more accessible spaces.... Ps1 ...to collaborate together...N3... I feel that there should be a wider area, so that parents could spend more time here...N5

In the view of staff, parents have difficulty understanding information and developing competence in childcare, so the staff believe that it is necessary to teach parents baby care while in the hospital.: ...(to teach parents) how to take care of their baby, so he may have better growth even when he is inside an incubator or in an open crib ...N2 ...(to inform them) before birth. If there were complications at the time of delivery, to explain to them the risks and care of a premature infant, to make her (the mother) more of a participant ...D3

Among the guidance provided to mothers, nurses focus on childcare, mainly concerning issues of early stimulation and maternal care: ...the mother is taught that she can pat him, change the diaper, make the baby perform active and passive exercises, can give him a massage (watching) venoclysis, provide auditory stimulation, and bring a music box so the baby can listen to it to relax...N2

It is also considered important to provide guidance in promoting maternal home care skills: ...(when participating) mom is aware that the baby is fed every three hours, she must change his clothes, bathe him, take care of him, and watch for anything that arises... we (nurses) give them signs and symptoms depending on the baby's health status at the time of discharge regarding home care...N5

Regarding the insufficient space in the NU, the staff proposed the modification of regulations and the redesign of the environment and space of the NU: ...(It must) be an exclusive area for the neonate in growth and development or premature, in which their parents could enter and watch them, and also change the hospital rules relating to that ...N4

To promote participation, the practitioners emphasized the importance of empathy and understanding of the parents' experiences in the NU: ...Where is the parents' suffering? The child is seriously ill, then he needs a special device (that) also encourages fear in parents. (they ask) What will happen when the child returns home? (parents say) "I don't have that device, he is going to die" ...Ps1 ...Parents are often anxious when they know their baby is a premature infant, when they are not seeing the evolution of their patient, which creates a conflict (for the health team) ...SW1. In addition to understanding the parents, the provision of some amenities so they can see the baby is also important: ...80\% are from rural areas, and this implies difficulties for the mom to come... many times because of the decision to come and return (it 
makes it difficult)... still, they are given food, and there are cases of ladies who are spending the night (here), not a high percentage, but we do have it...D1

\section{Discussion}

The study had the purpose to identify and analyze the meanings, beliefs and attitudes of neonatal unit staff about the Mexican parents' participation in care for hospitalized preterm neonates. In this sense, the parents' participation in the care of hospitalized preterm infants means benefits for the dyad mother-child. Staff considers that there are restrictions and barriers; some of them concerning to the staff and others to the institution. However, the staff provides some facilities and thinks that several rules and styles of work should change to favor participation.

Among the benefits of participation, for the health team the maternal participation is relevant, especially in breastfeeding functions - which provides nutritional benefit - In addition, the staff emphasized the promotion of the child's evolution and neurodevelopment, the establishment of bonding and attachment within the dyad, and reducing the days of hospitalization. This point of view is in accordance with another qualitative study in San Luis Potosí ${ }^{[6]}$.

They also emphasized the father's right to participate in the care of his child although they consider that the father is less participative than the mother, and the father has low participation especially during his work hours. Findings in a qualitative study showed that the hospital system does not allow the fathers to have access to the NU because they consider them as a vehicle of infections ${ }^{[20]}$. In developed countries, studies have shown that there is a gender difference with respect to participation ${ }^{[22]}$. The findings of a quantitative study of visits and parental participation at a tertiary-level NU in the UK emphasized that the mother stays longer and is more thoroughly engaged in caring for the child, including feeding, interaction, and hygiene, compared to the father. Conversely, another study supported the psychoanalytic perspective, stating that the father already shows his emotional face, is more present, and identifies with the contemporary demands of the family ${ }^{[23]}$. This reconstruction makes us think, that for some physicians and nurses, the inclusion of the father in the care of the premature neonate in the NU is relevant, pointing towards a possibility of expansion of care in the institution.

The themes that emerged regarding participation restrictions and barriers, including those related to the staff and institution (schedules, rules, space). The health personnel consider whether the parents touched their child, it could produce clinical destabilization. Similar meanings were found in a qualitative study in México ${ }^{[6]}$. However, the visit can be allowed in the case that the baby has a bad prognosis and when the nurse perceives the parents are really interested in their child, since the staff has also perceived lack of interest on the parents' side.

The health team emphasized the obstacles for the visit produced by institutional work schedules and routines, for example the round of doctors, taking laboratory samples and x-rays, all of them occurring in the morning shift, thus, they think that the attachment could be favored during the evening shift; however, in general, nurses mentioned there is a lack of personnel and this limits the attention to the parents as well. In Swedish NUs occur that participation also fluctuates according to the vision of the staff and to the medical-technological and environmental care routines ${ }^{[7]}$. It has been mentioned by nursing in a qualitative study, stating that the parents interfere in the work dynamics ${ }^{[6]}$. In addition, in the perspective of health professionals, the space in the NU is also a limiting factor. In contrast, the staff proposes the modification of regulations and the redesign of the environment and space, including the provision of some amenities. In this sense, there are current initiatives such as the architectural redesign of the neonatal unit, to provide better care and support to parents due to the increasing awareness of philosophies, including family-centered care and a family-friendly environment, which reflects in several countries a change in attitude with respect to the neonatal care unit ${ }^{[24]}$.

The parents' participation means to the staff to cope with the parent's emotions, thus, the mothers can be anxious and argue with nurses demanding information about their babies. Staff must also consider the parents' feelings, including the therapeutic aspects of mourning management. Parents' experiences in the NU involve suffering and hope when coping 
with the hospitalization of their child, along with satisfying the child's and their own emotional needs, as shown in qualitative studies from México, China and Australia ${ }^{[20,25,26]}$.

Additionally, this study highlights the reductions in maternal anxiety and conflicts with the nursing staff when the mother receives information or can be in contact with her child. In accordance, Sousa, recommended effective communication between parents and the health team ${ }^{[27]}$. Wigert found that parents felt better when they found a family-friendly NICU environment, and they also expressed feelings of happiness and satisfaction when the staff welcomed them ${ }^{[9]}$. In a study conducted in Sweden, an oncology service had a work routine that systematized working with parents and found that they were less stressed compared to other pediatric wards in which there was no such systematization. When working with parents is systematized, it can reduce the stress on the health professionals, and, therefore, the conflicts between parents and staff ${ }^{[28]}$.

The health professionals highlighted a barrier when the mother is an adolescent, because it is associated with difficulties to learn about the care of her child. The staff emphasized these mothers have poor understanding of care guidelines. On the other hand, a study reveals the point of view of adolescent mothers who mentioned that the first information received about their child was given by nurses, then by doctors who spoke with complicated language and produced reluctance to speak with health professionals to ask or clarify information. The emotions and elements of communication can be factors that diminish cognitive abilities of parents. At the same time, the interviewees mentioned that they prefer to talk with the adolescents' mothers to guarantee that an adult understands the guidelines. In this sense, Boss et al. mentioned that their experience is to establish communication with an adult in the family as well ${ }^{[29]}$.

In the perspective of a social worker, living in a rural area is a barrier because the parents live far away or do not have money to travel and visit their hospitalized child; situation highlighted in the perspective of parents in the qualitative study ${ }^{[21]}$, and meaning parents negligence to the social worker. From the nursing perspective, parents from rural areas are not suitably prepared for the contact with their child because of their poor hygiene, which similarly happens in another $\mathrm{NU}{ }^{[6]}$.

The vulnerable population, generally with poor education and rural origin, has little initiative to participate, this in a perspective of health team. Indigenous and European cultural mixture from the conquest is still present in México. In this mixture submissiveness prevails. Thus, in regards to the poor initiative for parents' participation, this inclination may be linked to factors other than socio-demographic and economic characteristics, and because the parents assume they are below the medical hierarchy ${ }^{[20,30]}$. Similarly in a 100-family study, the caregivers represented one-third of all family caregivers of hospitalized children in another developing country, and most of them had a low level of education and poor socio-economic conditions ${ }^{[31]}$. Parents stated that they were subordinated to the authority represented by the staff. The time in the hospital is difficult to both cope with and understand. However, the choice to allow entry of parents and their participation in care could be a matter of control and exercising power, as the professional authority is recognized and accepted by parents for their capacity and organizational power to solve their problems. The power in professionalpatient/parent relationships has been well documented ${ }^{[32]}$. The parents might not see their participation as a right but might instead be submissive to authority ${ }^{[33]}$.

Despite these constraints, it is important for the health care team to encourage the parents to learn about care, especially the care required at home after discharge, nevertheless, this assistance even though it is not yet systematized ${ }^{[6]}$. Education is also a necessity for parents in the NU, because the parents feel excluded and they perceive they do not have competences in caring for their child ${ }^{[20]}$. We believe that the presence of parents is very important for the development and learning of their parental role behavior and to foster their attachment to their child. From the perspective of Gardner, the staff would teach and work closely with the parents to achieve care competency; therefore, they would be accompanied by the team and by other parents ${ }^{[34]}$. In addition, Merighi stated that nurses need to have interpersonal competency to care for a baby 
and his family ${ }^{[35]}$. In fact, NUs have attempted to expand parental roles by adopting unrestricted visitation rights and encouraging parental participation in care, based on the benefits of affectionate handling for the most fragile babies ${ }^{[36]}$.

\section{Conclusions}

The staff interviewed in this study considered parental participation important, and they proposed some changes to promote participation based on a system of teamwork and the transformation of hospital rules. From a psychological perspective, the health care professionals proposed emphasizing the experiences of parents in the NU and supporting their derived emotions and feelings.

Regarding parental education, the participants thought that they should be teaching about childcare. However, contradictions among the practitioners were revealed regarding parental involvement mediated by gender, particularly the idea that the mother is the main presence and the father is the recipient of information, despite expressing the importance of the father's inclusion and his right to take care of his child. This contradiction leads us to consider the possibility of ideological changes concerning the father's role, as these transformations have already started at the social level in the new family organization.

The weight of the lack of participation might not be due only to the profile of the population assisted. We must also consider that practitioners did not mention support initiatives or strategies to achieve the inclusion of parents. In addition, we consider that these strategies must be built by the subjects involved in care, the managers, the staff, and the families who receive such care (the babies and their parents).

The concept of participation in Latin American culture should be analyzed. The participation of parents with hospitalized children in México has different connotations than those published in research in developed countries. In our study, there is still a lack of analysis concerning other factors affecting participation. These factors should be investigated to develop more and better strategies to promote parental participation in hospitals in México.

How might this information affect nursing practice? Premature neonates are a vulnerable population; biotechnological advances allow them to survive from very early gestational ages, and their prolonged hospitalizations require separations from their families. This situation has given rise to the application of programs that promote parental participation in the neonatal unit (NU) and thereby benefit the clinical evolution and development of preterm infants, their bonding and attachment, and the competence of the parents at providing infant care, leading also to a reduction in the days of hospitalization. Parental visits to NUs in México should not depend on the following factors: human milk production, neonate clinical conditions, and medical treatment. We recommend designing an institutional program with a philosophy and framework that is focused on family-centered care and considers the perspective of all participants (parents, nurses, and doctors) to promote parents' integral participation in the care of hospitalized preterm infants in the NU who require an increase in their quality of life.

\section{References}

[1] Beck S, Wojdyla D, Say L, Betran AP, Merialdi M, Harris-Requejo, et al. The worldwide incidence of preterm birth: a systematic review of maternal mortality and morbidity. Bulletin of the World Health Organization. 2010; 88: 31-38. Available from: http://who.int/bulletin/volumes/88/1/08-062554/en/

[2] Stephens BE, Vohr BR. Neurodevelopmental Outcome of the Premature Infant. Pediatric Clin North Am. 2009 ; 56: 631-646. Available from: http://www.ncbi.nlm.nih.gov/pubmed/19501696

[3] Villalobos MS, Carrasco MT. Recuperación del peso de nacimiento en recién nacidos pretérmino menores de 1500 gramos. Archivos de Investigación Materno Infantil. 2011; 3(2): 59-66. Available from:

http://www.medigraphic.com/pdfs/imi/imi-2011/imi112b.pdf 
[4] Subdirección de Informática y Estadísticas en Salud. Subsistema de información sobre nacimientos San Luis Potosí, México; 2011. Available from: http://www.cemece.salud.gob.mx/descargas/pdf/SINAC_2008_2012.pdf

[5] Flacking R, Lehtonen L, Thomson G, Axelin A, Ahlqvist S, Moran VH, et al. Closeness and separation in neonatal intensive care. Acta Pædiatrica. 2012; 101: 1032-1037. Available from: http://www.ncbi.nlm.nih.gov/pubmed/22812674 PMid:22812674 http://dx.doi.org/10.1111/j.1651-2227.2012.02787.x

[6] Gallegos-Martínez J, Fonseca LMM, Scochi CGS. The participation of parents in the care of premature children in a neonatal unit: meanings attributed by the health team. Rev. Latino-Am. Enfermagem. 2007; 15 (2): 239-246. Available from: http://www.ncbi.nlm.nih.gov/pubmed/17546355

[7] Wigert H, Hellström AL, Berg M. Conditions for parents' participation in the care of their child in neonatal intensive care - a field study. BMC Pediatrics. 2008; 8(3): 9. Available from: http://www.biomedcentral.com/1471-2431/8/3

[8] Zack Boukydis Parent-infant skin-to-skin contact: parents’ views versus nurses’ views Acta Pædiatrica a2011 Foundation Acta Pædiatrica. 2011; 100: 638-640. PMid:21371119 http://dx.doi.org/10.1111/j.1651-2227.2011.02195.x

[9] Wigert H, Berg M, Hellström AL. Parental presence when their child is in neonatal intensive care. Scand J Caring Sci. 2010; 24: 139-146. PMid:19508328 http://dx.doi.org/10.1111/j.1471-6712.2009.00697.x

[10] Heermann LA, Wilson ME, Wilhelm PA. Mothers in the NICU: Outsider to Father. Pediatric Nurs. 2005; 31(3): 176-200. PMid:16060580

[11] Liaw J, Yang L, Chang LH, Chou LH, Chao ShCh. Improving neonatal caregiving through a developmentally supportive care training program. Applied Nurs Research. 2009; 22: 86-93. Available from: http://www.sciencedirect.com/science/article/pii/S0897189707000699 PMid:19427569 http://dx.doi.org/10.1016/j.apnr.2007.05.001

[12] Wigert H, Dellenmark MB, Bry K. Strengths and weaknesses of parent-staff communication in the NICU: a survey assessment. BMC Pediatrics. 2013; 13: 71. Available from: http://www.biomedcentral.com/1471-2431/13/71 PMid:23651578 http://dx.doi.org/10.1186/1471-2431-13-71

[13] Power N, Franck L. Parent participation in the care of hospitalized children: a systematic review Journal of Advanced Nursing. 2008; 62(6): 622-641. PMid:18503645 http://dx.doi.org/10.1111/j.1365-2648.2008.04643.x

[14] Pongjaturawit Y, Harrigan R. Parent participation in the care of hospitalized child in thai and western cultures. Issues Compr Pediatr Nurs. 2003; 26: 183-199. Available from: http://www.ncbi.nlm.nih.gov/pubmed/12936700 PMid:12936700 http://dx.doi.org/10.1080/01460860390223934

[15] Gallegos-Martínez J, Reyes-Hernández J, Scochi CGS. La Unidad Neonatal y la participación de los padres en el cuidado del prematuro. Perinatol Reprod Hum. 2010; 24(2): 98-108. Available from: http://www.eerp.usp.br/media/wcms/files/ip102b.pdf

[16] Sandelowski M. Focus on Research Methods Whatever Happened to Qualitative Description? Research in Nursing \& Health. 2000; 23: 334-340. http://dx.doi.org/10.1002/1098-240X(200008)23:4<334::AID-NUR9>3.0.CO;2-G

[17] Morse JM, Field PA. Qualitative research methods for health professionals. 2nd. Edition. USA: SAGE Publications International Educational and Professional Publisher.

[18] Minayo MCS. O desafío do conhecimento. Pesquisa qualitativa em saúde. $7^{\text {a }}$ ed. São Paulo (SP): Hucitec-Abrasco; 2000.

[19] Mexican Official Standard NOM-007-SSA2-1993 medical attention for pregnancy woman, woman in labor and post-labor and newborn. http://dof.gob.mx/nota_detalle.php?codigo=5276550\&fecha=05/11/2012

[20] Gallegos-Martínez J, Reyes-Hernández J, Scochi CGS. The hospitalized preterm newborn: The significance of parents' participation in the Neonatal Intensive Care Unit. Rev. Latino-Am. Enfermagem. 2013; 21(6): 1360-1366.

[21] Bardin L. Analise de conteúdo. Lisboa Edições; 1977.

[22] Franck LS, Spencer C. Parent visiting and participation in infant caregiving activities in a neonatal unit. Birth. 2003; 30(1): 31-35. Available from: http://www.ncbi.nlm.nih.gov/pubmed/12581037 PMid:12581037 http://dx.doi.org/10.1046/j.1523-536X.2003.00214.x

[23] Gomes AJS, Resende VR. The present father: discovering the fatherhood in a contemporary family. Psicologia Teoria e Pesquisa. 2004; 20(2): 119-125.

[24] Rybkowski ZK, Shepley MM, DArch, Ballard HG. Target value design: applications to newborn intensive care units. HERD. 2012; 5(4): 5-22. https://www.herdjournal.com/article/target-value-design-applications-newborn-intensive-care-units

[25] Lam LW, Chang AM, Morrissey J. Parents' experiences of participation in the care of hospitalized children: a qualitative study. Int J Nurs Stud. 2006; 43(5): 535-45. Available from: http://www.sciencedirect.com/science/article/pii/S0020748905001604 PMid:16143333 http://dx.doi.org/10.1016/j.ijnurstu.2005.07.009

[26] Trajkovski S, Schmied V, Vickers M, Jackson D. Neonatal nurses’ perspectives of family-centred care: a qualitative study. J Clin Nurs. 2012; 21: 2477-2487. Available from: http://www.ncbi.nlm.nih.gov/pubmed/22889445 PMid:22889445 http://dx.doi.org/10.1111/j.1365-2702.2012.04138.x 
[27] Sousa P, Antunes A, Carvalho J, Casey A. Parental perspectives on negotiation of their child's care in hospital. Nurs Children Young People. 2013; 25(2): 24-28. Available from: http://www.ncbi.nlm.nih.gov/pubmed/23586180

[28] Ygge BM, Lindholm C, Arnetz J. Hospital staff perceptions of parental involvement in paediatric hospital care. J Adv Nurs. 2006; 53(5): 534-542. Available from: http://www.ncbi.nlm.nih.gov/pubmed/16499674 PMid:16499674 http://dx.doi.org/10.1111/j.1365-2648.2006.03755.x

[29] RD Boss, PK Donohue2, 3 and RM Arnold. Adolescent mothers in the NICU: how much do they understand? Journal of Perinatology. 2010; 30: 286-290. PMid:19812590 http://dx.doi.org/10.1038/jp.2009.160

[30] Gallegos-Martínez J. A precious jewel: Signify (meaning) of child care in México. Text \& Context Nurs. 2006 ; 15 (Special Issue): 146-151. Available from: http://www.scielo.br/scielo.php?pid=S0104-07072006000500017\&script=sci_arttext

[31] Söderbäck M, Christensson K. Family involvement in the care of a hospitalised child: a questionnaire survey of Mozambican family caregivers. Int J Nurs Stud. 2008; 45(12): 778-88. Available from: http://www.ncbi.nlm.nih.gov/pubmed/18657810 PMid:18657810 http://dx.doi.org/10.1016/j.ijnurstu.2008.06.008

[32] Fegran L, Helseth S. The parent-nurse relationship in the neonatal intensive care unit context - closeness and emotional involvement. Scand J Caring Sci. 2009; 23: 667-673. Available from: http://www.ncbi.nlm.nih.gov/pubmed/19000088 PMid:19000088 http://dx.doi.org/10.1111/j.1471-6712.2008.00659.x

[33] Machado MFAS, Vieira NFC. The mothers' participation in the child malnutrition program. Rev. Latino-Am. Enfermagem. 2004; 12(1): 76-82. http://dx.doi.org/10.1590/S0104-11692004000100011

[34] Gardner MR. A relevant intervention model for parents of vulnerable newborn infants. Pediatr Nurs. 2013; 39(1): 47-48.

[35] Merighi MAB, Pinto de Jesus MC, Santin KR, Oliveira DM. Caring for newborns in the presence of their parents: the experience of nurses in the neonatal intensive care unit. Rev. Latino-Am. Enfermagem. 2011; 19(6): 1398-404. Available from: http://www.ncbi.nlm.nih.gov/pubmed/22249675

[36] Davis, L., Mohay, H., Edwards, H. Mothers' involvement in caring for their premature infants: an historical overview. Journal of Advanced Nursing. 2003; 42(6): 578-86. PMid:12787231 http://dx.doi.org/10.1046/j.1365-2648.2003.02661.x 